\title{
$\mathrm{TRIZ/CAE}$ 를 활용한 철도차량 윤축용 캡의 창의적 설계
}

\author{
허용정 ${ }^{*}$, 김재민 ${ }^{1}$, 홍성도 $^{2}$ \\ ${ }^{1}$ 한국기술교육대학교 메카트로닉스공학부 \\ ${ }^{2}$ 한국기술교육대학교 대학원 메카트로닉스공학과
}

\section{Creative Design of Cap for Wheel and Axle of Railway Vehicle by Using TRIZ/CAE}

\author{
Yong-Jeong Huh ${ }^{1 *}$, Jae-Min Kim ${ }^{1}$ and Sung-Do Hong ${ }^{2}$ \\ ${ }^{1}$ School of Mechatronics, Korea University of Technology and Education \\ ${ }^{2}$ Graduate School of Mechatronics, Korea University of Technology and Education
}

\begin{abstract}
요 약 철도차량의 안전성을 위해 사용되는 윤축은 차량 전체 중량의 $16 \%$ 를 차지하는 요소로서, 철도차량의 경량 화에 있어 필수적으로 연구되는 대상이다. 본 연구는 기존 윤축의 중량을 요구강도에 만족시킴과 경량화를 목적으로 창의적 문제해결이론인 TRIZ의 $6 \mathrm{SC}$ 를 적용하여 중공구조의 윤축 내부에 사용될 수 있는 캡을 설계하였고, 설계에 대한 검증을 위해 해석 툴인 ANSYS를 활용하였다. 본 연구에서 제안한 캡의 재질은 $\mathrm{SM} 45 \mathrm{C}$ 이며 중공구조이다. 또 한, 윤축에 요구되는 강도를 만족하기 위해 중공 윤축의 베어링 시트 부 내부에 위치한다. 본 연구를 통해 설계 및 해석된 캡을 삽입한 윤축은 전동차의 윤축에 요구되는 기준을 만족하였으며 무게는 중실축과 비교하였을 때, 약 $6.75 \%$ 를 감소시켰다. 윤축 강도에 대한 평가 기준은 EN13103 및 EN13104의 규격을 적용하였다. 또한, 캡을 장착한 윤축의 최대응력 및 중량에 대해 기존의 중실축, 중공축과 비교함으로써 설계에 대한 효과를 검증하였다.
\end{abstract}

\begin{abstract}
This paper aims at the design of wheel and axle with cap. The cap is conceptually designed by using TRIZ/CAE. Wheel axle is used at railway vehicle to safety and it is always investigated to reduce the railway vehicle weight. The cap has hollow shaft with the material of SM45C. Cap is located in the bearing seat of wheel and axle. The cap becomes durable within the allowable stress of EN13103, 13104 standard. In this study, the strength of wheel and axle with cap becomes higher than that of hollow shaft. The weight of wheel and axle with cap becomes lower by about 6.75 percent than that of solid shaft. The confidence of wheel and axle with cap can be improved by comparing with solid and hollow shafts.
\end{abstract}

Key Words : CAE, Cap, TRIZ, Wheelset, Wheel and Axle

\section{1. 서론}

철도차량의 윤축(Wheel and Axle)은 차륜과 차축으로 구성되어 있으며 차체를 지지하는 기능을 수행한다. 차축 의 지지기능이 불충분하여 이의 파손이 발생할 경우, 탈 선으로 인한 중대 사고를 유발하며 이는 인명 피해 및 재 산 피해 등으로 연결된다. 따라서 철도차량의 윤축은 상 기 지지기능을 수행하기 위해 요구되는 강도를 만족해야
한다.

차체로부터 윤축이 받는 힘은 철도차량의 중량에 의한 수직하중과 곡선 구간을 운행할 때 차륜과 레일의 접촉 부에서 수평하중이 발생하며 견인 전동기의 토크 및 제 동 디스크와 차륜에 가해지는 제동력이다[1].

윤축은 상술된 힘을 지지하기 위해 각 하중에 의한 비 틀림, 굽힘 및 전단 응력, 반복 응력으로 인한 피로 등을 고려하여 설계되어야 한다.

\footnotetext{
본 논문은 2013년도 한국기술교육대학교 교수 교육연구진흥비 연구 지원에 의해 연구되었음.

"Corresponding Author: Yong Jeong Huh(Korea University of Technology and Education)

Tel: +82-41-560-1135 email: yjhuh@koreatech.ac.kr
}

Received April 4, 2013

Revised (1st May 9, 2013, 2nd May 20, 2013)
Accepted June 7, 2013 
윤축의 강도와 강성을 만족하기 위해 축의 단면적을 증가시키면 하중이 증가하여 기술적, 비용적인 문제를 야 기한다. 윤축은 [Fig. 1]과 같이 철도차량 전체 중량 중, 약 $16 \%$ 의 중량을 차지하며 세 번째로 무거운 요소이다. 한국형 표준전동차는 1999년에 국내 기술로 설계 및 생 산한 도시철도 차량으로 동력 분산식 (Electric Multiple Unit, EMU)으로서 K-EMU이라 약칭한다. 윤축의 질량은 철도차량의 서스펜션 하부에 위치한 스프링하질량 (unsprung mass)이며, 이의 중량이 감소할수록 철도차량 의 주행 성능과 주행으로 인한 소음 및 진동을 감소시키 는 효과가 있다. 또한 철도의 연료 소비를 줄임으로써 친 환경성과 에너지 소비효율의 극대화를 이룰 수 있다[2,3].

본 연구에서는 TRIZ의 $6 \mathrm{SC}$ 기법을 활용하여 기존 윤 축이 가지는 문제점을 명확히 정의하였고 윤축 내부를 이루는 캡(Cap) 구조를 설계하였다. 이에 대한 검증으로 서 유한요소법 상용 소프트웨어인 ANSYS Workbench를 활용하여 캡 구조를 가진 윤축에 걸리는 응력을 해석하 였고 기존 윤축과 비교함으로써 설계의 신뢰성을 검증하 였다.

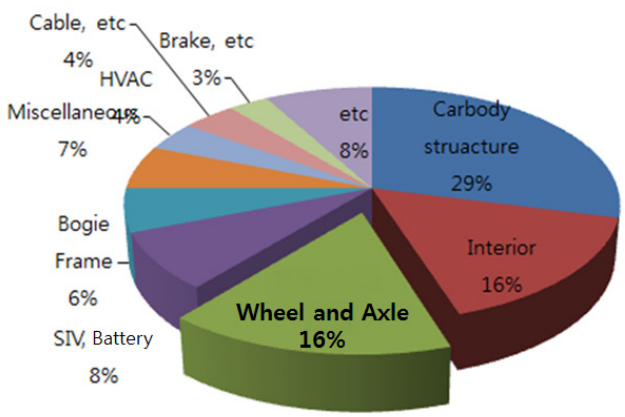

[Fig. 1] Weight distribution of EMU system

\section{2. 이론}

\section{1 트리즈}

트리즈(TRIZ)는 러시아어로 “창의적 문제해결 이론 (Theory of Inventive Problem Solving)의 약자이다. 트리 즈는 수십만 건의 특허 분석을 통해 정립된 발명의 패턴 을 포함하며, 이를 도구화하여 일반인들도 발명을 할 수 있도록 하는 창의적 문제해결기법이다.

트리즈의 특징은 기술문제에 존재하는 모순(시스템이 요구 받는 상호 배타적 특성)을 타협하지 않고 추가적인 시스템의 도입 없이 문제를 해결하는데 있다. 또한 기존 의 방법론에서 흔히 사용하는 시행 착오법을 지양하고
문제해결 프로세스를 통하여 문제해결의 가이드라인을 제공한다.

본 논문에서 활용한 트리즈의 문제해결기법은 $6 \mathrm{SC}$ 이다. $6 \mathrm{SC}$ 는 자신의 경험과 지식에 의한 사고관성을 제거하 고 새로운 방향으로 문제를 창의적으로 풀어가게 한다. 이 과정에서 고정관념은 제거되고 자신의 지식과 타인의 지식을 활용해야 하는 시점이 언제인지 알 수 있다[4].

$6 \mathrm{SC}$ 는 1) 그림으로 표현, 2) 시스템 기능분석 3) 이상 해결책 (IFR) 가정하기, 4) 모순과 분리원리, 5) 요소-상 호 작용 6) 해결책 평가 등으로 구성되어 있다[5].

\section{2 유한요소법}

유한요소법은 1940년대에 처음으로 구조역학 분야에 등장한 수치해석 방법이다. 스위스의 수학자 Bernoulli가 개발한 “일차연립방정식의 매트릭스해법”과 계산기의 뛰 어난 계산능력을 바탕으로 하는 방법은 1950 년대의 후반 부터 1960년대에 걸쳐서 발전을 이루었으며, 구조역학문 제를 쉽게 응력 및 변위 등으로 풀 수 있었다. 유한요소 법은 에너지 원리에 출발점을 두고 있다.

유한요소법은 해석하고자 하는 구조물을 유한요소라 고 불리는 기하학적 구조로 대체한 다음, 시스템의 에너 지에 대하여 물리학적 원리를 적용함으로써 시스템의 통 제방정식을 매트릭스 형식으로 도출한다[6].

\section{3. 연구결과}

본 연구에서 수행한 차축 설계 및 강도 평가에 대해 국제적으로 철도차량의 축에 사용되고 있는 EN13103 및 $\mathrm{EN} 13104$ 의 규격을 설계의 기준으로 적용하고 차축 응력 평가를 하였으며 이를 한국형 표준 철도차량(K-EMU)에 적용하였다[2,3].

\subsection{TRIZ 6SC기법을 이용한 윤축설계}

\subsection{1 그림으로 표현}

$6 \mathrm{SC}$ 의 첫 번째 단계는 문제 해결을 그림으로 표현하 는 것이다. 이는 문제 상황의 도식화를 통해 기술적 표현 으로 정의하는 과정이다. 그림으로 표현함으로써 문제의 상황을 쉽게 분석하고 문제의 원인을 찾을 수 있다. 윤축 의 하중 감소를 위한 문제의 그림은 [Fig. 2]와 같다.

윤축에 대한 문제 상황은 다음과 같다. 윤축에 작용하 는 하중들(수직력, 수평력, 견인 전동기의 토크 및 제동 력)을 지지하고 최소한의 중량을 갖기 위해 개발된 중공 축의 베어링 시트 부(seats except axle bearing)는 차체의 
하중에 대하여 응력이 집중되어 강도에 대한 안전성이 떨어짐을 알 수 있다.

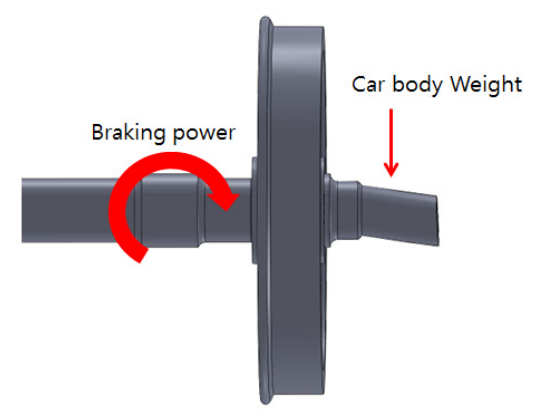

[Fig. 2] Picture of wheel and axle structure

\subsection{2 시스템 기능분석}

시스템 기능분석은 기술시스템의 상호작용이 복잡하 게 일어나거나 문제가 명확하지 않은 경우, 유용하게 사 용될 수 있으며 이는 기술시스템, 목표대상 및 환경요소 로 구성된다.

문제 상황의 시스템 구성요소들과 주변 환경들의 상호 관계를 정의함으로써 시스템 내에 작용하는 유용한 기능 과 유해한 기능을 정의한다.

본 연구의 시스템 기능분석은 [Fig. 3]과 같다.

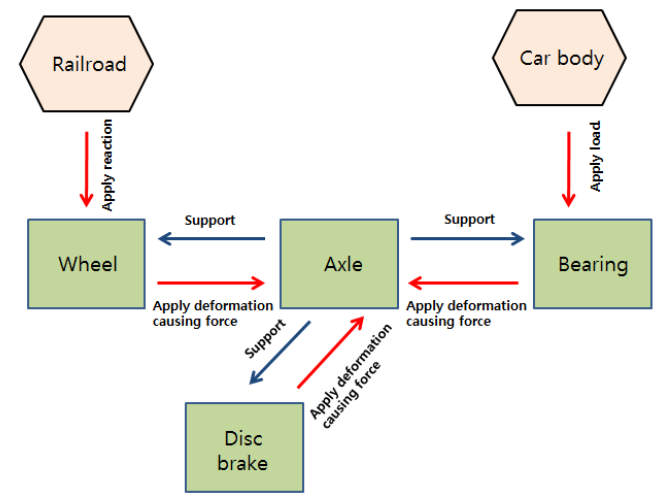

[Fig. 3] Analysis of wheel and axle system

윤축은 차체와 철로 등의 외부환경과 직접적인 상호작 용을 한다. 이 때, 차체하중 및 디스크 브레이크의 제동력 이 차축에 전달되므로 차축에 응력이 발생한다.

윤축의 유해한 작용인 차축에 가해지는 힘을 유익한 작용으로 변환하기 위해서는 이를 개선하거나 제거해야 한다.

시스템 기능분석을 통해 윤축의 시스템 및 환경 요소
들을 명확히 파악하였고, 문제를 유발하는 유해한 요소를 도출하였다[7].

\subsection{3 이상해결책 가정하기}

이상해결책은 다른 기능의 저하 없이 유용한 기능을 달성하거나, 하나의 유해한 기능의 제거가 다른 유해한 기능의 출현 없이 달성하는 것이다[6].

시스템 기능분석에 따르면 윤축의 유해 작용인 차축에 가해지는 힘을 제거하거나 개선하여 문제를 해결해야 하 지만 윤축 시스템은 차축에 가해지는 힘은 필연적으로 발생하는 제한조건을 가진다.

따라서 본 연구의 이상해결책은 차체의 하중 및 제동 력이 차축에 가해져도, 차축의 응력이 $\mathrm{EN}$ 규격 이하로 감 소하는 것이다.

\subsection{4 모순과 분리 원리}

TRIZ의 중요한 개념인 모순에는 기술적 모순과 물리 적 모순이 있다. 기술적 모순(technical contradiction)이란 서로 다른 두 가지 기술적 특성이 서로 충돌하는 것이다. 이는 TRIZ에서 제공하는 모순 매트릭스, 40가지 발명원 리 등을 활용하여 해결할 수 있다[7].

본 연구의 기술적 모순은 차축의 중량을 감소시키면, 강도가 나빠지는 것으로 정의할 수 있으며, 모순 매트릭 스에서 제안하고 있는 발명원리는 진동이용(no.18), 한번 쓰고 버리기(no.27), 기계시스템을 대체하기(no.28), 복합 재료 이용(no.40)이다.

진동이용의 원리를 사용하면, 윤축의 회전 시 발생하 는 응력의 파형 간 상쇄를 위한 진동발생의 개념을 도출 할 수 있다.

한번 쓰고 버리기의 원리를 사용하면, 중공축에서 파 손된 부분을 탈부착 하는 형태로 하여 교체하는 개념을 도출할 수 있다.

기계시스템을 대체하기의 원리를 사용하면, 기존의 윤 축을 전자기장의 반발력을 이용한 시스템으로 변환 도출 할 수 있다.

복합재료 이용의 원리를 사용하면, 윤축의 내부 구조 를 허니콤 또는 다공질의 재료로 대체의 개념을 도출할 수 있다.

물리적 모순(physical contradiction)은 어떤 하나의 기 술적 변수가 서로 다른 값을 동시에 가져야 하는 것이다.

기술적 모순으로부터 도출된 해결책은 중공축의 내부 구조를 복합재료로 대체하는 것이다.

본 연구의 물리적 모순은 다음과 같다.

차축에 요구되는 강도를 만족하기 위해서는 중공축 내 부에 복합재료가 있어야 하지만 차축의 중량 감소를 위 
해서는 복합재료가 없어야 한다.

TRIZ는 물리적 모순에 대한 해결방법으로서 분리에 의한 원리를 제안한다. 분리에 의한 원리는 시간에 의한 분리, 공간에 의한 분리, 조건에 분리, 전체와 부분에 의 한 분리가 있다.

윤축에 대한 물리적 모순을 해결하기 위한 분리 원리 는 공간에 의한 분리를 적용하였다.

중공 구조를 갖는 윤축에 원통형 캡을 삽입하되 $\mathrm{EN}$ 규격에서 규정하고 있는 허용 응력을 초과하는 부위에만 적용하고, 이외의 부위에는 중공 구조로 설계하여 중량을 감소시킨다.

\subsection{5 요소 상호작용}

요소 상호작용은 문제를 구성하는 두 개의 핵심 요소 를 찾고 각 요소들의 물리적 성질을 기록하며 단계적으로 각 요소의 상호 작용에 따라 해결책을 찾는 방법이다[6].

본 연구의 요소 상호 작용은 [Fig. 4]와 같다.

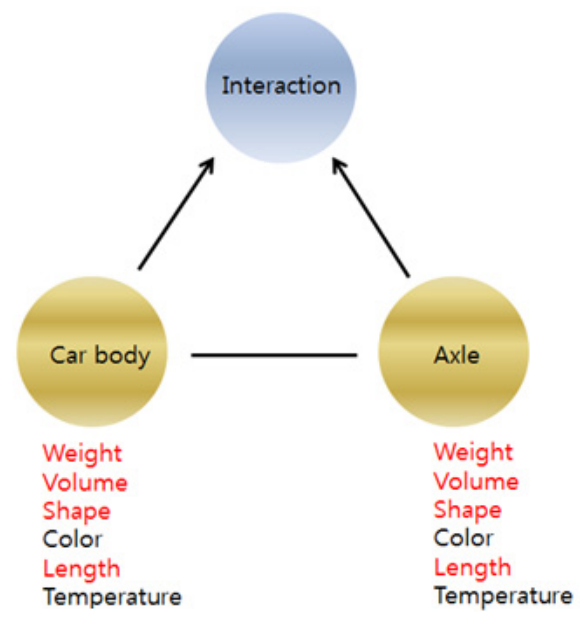

[Fig. 4] Interaction of Elements

차체 성분 중 하중과 차축 성분 중 구조의 상호 작용 을 고려하여 해결책을 도출 하면 다음과 같다.

차체의 하중이 차축에 주어 질 때, 중공 구조를 갖는 차축의 내부구조가 하중을 분산 및 지지한다면 강도를 높이면서 가벼운 중량을 만족할 수 있다.

\subsection{6 해결책 평가}

해결책 평가 과정은 $6 \mathrm{SC}$ 의 각 단계를 활용하여 분석 및 도출한 여러 가지 해결책들 가운데 최종적으로 선택 하고 평가하는 것이다[7].

$6 \mathrm{SC}$ 분석을 통하여 제 3 의 요소로서 추가된 캡은 중
공의 차축에 EN13103 및 13104에서 규정하고 있는 허용 응력을 넘는 부분에 삽입한다.

캡은 부분적으로 차축의 강도를 보강하며, 기존 중공 구조를 갖는 차축의 가벼운 무게를 만족하고, 중실 구조 에 비해 중량이 감소될 수 있다.

\subsection{Ansys를 활용한 유한요소 해석}

\subsection{1 윤축에 대한 해석조건 및 영역}

본 연구에서 설계한 캡이 적용된 윤축에 작용하는 응 력과 중량에 대하여 기존의 중실구조 및 중공구조 윤축 과 비교 해석하였다.

일반적인 형태의 차축을 설계하는 경우에는 국제적으 로 통용되는 기준을 사용하기 때문에 본 연구에서 수행 한 차축의 응력 평가 및 설계는 $\mathrm{EU}(\mathrm{EN} 1310)$ 에서 규정 한 기준을 적용하였다.

[Table 1]은 K-EMU에 사용되는 윤축에 작용하는 하 중조건들을 나열한 것이다.

[Table 1] Loads for an axle of a K-EMU trailer [2]

\begin{tabular}{c|c}
\hline \hline Load & Magnitude (N) \\
\hline$P_{1}$ & 96,783 \\
\hline$P_{2}$ & 72,169 \\
\hline$Y$ & 47,307 \\
\hline$H$ & 23,654 \\
\hline$F_{i}$ & 839.25 \\
\hline
\end{tabular}

$P_{1,2}$ : 철도차량 하중에 의한 수직하중

$Y$ : 차륜과 레일 접촉부의 수평하중

$H$ : 수평하중으로 인한 횡압

$F_{i}$ : 제동 디스크로 인한 제동력

$\mathrm{EN}$ 의 규격에 따라 윤축의 각 부분에 허용되는 응력은 [Table 2]와 같다.

[Table 2] Permissible stress for a motor bogie axle defined in EN standard

\begin{tabular}{c|c|c}
\hline \hline \multicolumn{2}{c|}{ Axle type and zone } & $\begin{array}{c}\text { Permissible stress } \\
(\mathrm{Mpa})\end{array}$ \\
\hline \multirow{3}{*}{ Solid axle } & axle body, fillets & 166 \\
\cline { 2 - 3 } & seats & 100 \\
\hline \multirow{4}{*}{$\begin{array}{c}\text { Hollow } \\
\text { axle }\end{array}$} & axle body, fillets & 166 \\
\cline { 2 - 3 } & seats except axle bearing & 92 \\
\cline { 2 - 3 } & axle bearing & 78 \\
\cline { 2 - 3 } & bore & 67 \\
\hline
\end{tabular}

해석에 사용된 윤축의 도면은 [Fig. 5]와 같다. 차축과 차륜의 접합은 마찰을 무시한 Bonded를 사용하였다. 


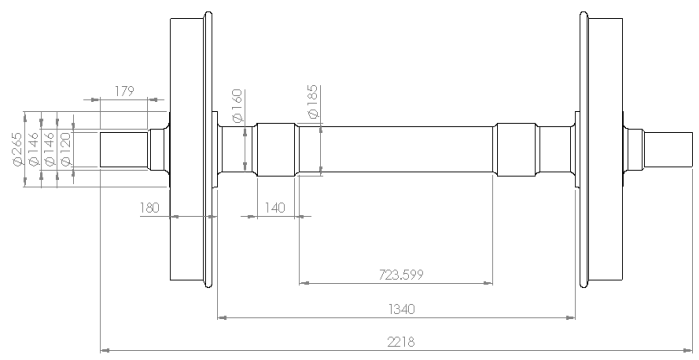

[Fig. 5] wheel and axle drawing

윤축의 해석에 사용된 재질은 STEEL R7 UIC812-3이 며 탄성계수 $205 G p a$, 푸아송 비(Poisson's ratio) 0.3의 물성치가 사용되었다[8].

윤축 모델링의 매쉬(mesh)는 크기 $10 \mathrm{~mm}$, 요소 수 118951 개, 노드 수 253960 개로 정의하였다. 이는 [Fig. 6] 과 같다.

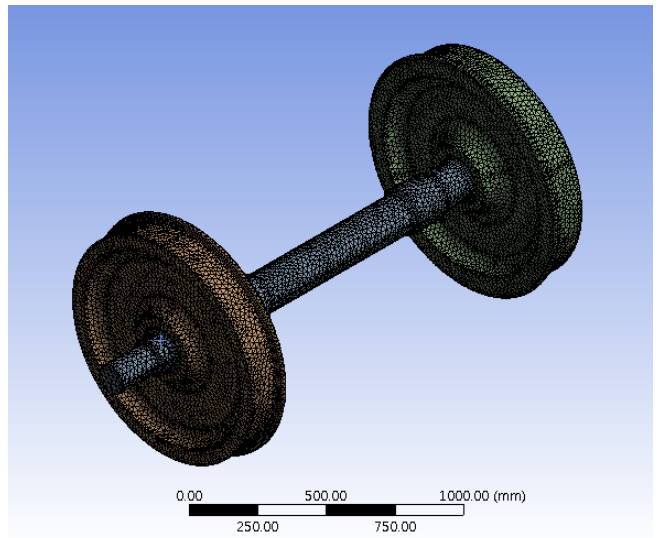

[Fig. 6] Mesh applied on the wheel and axle

유한요소법으로 윤축을 해석하기 위해서 하중 조건 및 구속 조건은 [Fig. 7]과 같다.

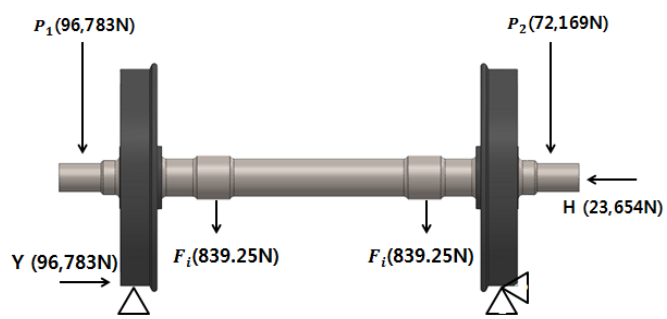

[Fig. 7] The load and foundation conditions of the axle

\subsection{2 해석 결과}

해석된 결과는 [Fig. 8]과 같다.

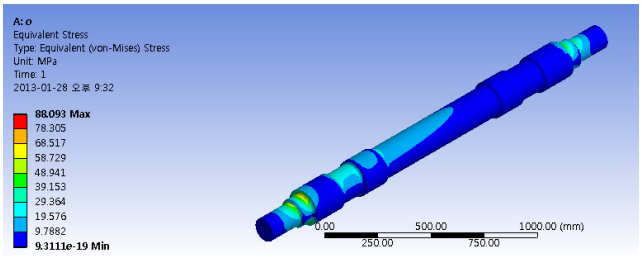

[Fig. 8] Analysis results for stress of K-EMU solid axles

중실축의 해석결과, 축의 몸체 및 필렛(fillets) 부의 최 대 응력 $66.237 \mathrm{Mpa}$, 베어링 시트 부의 최대 응력 88.093 Mpa, 중량 $13.505 \mathrm{kN}$ 로 도출되었다.

내경 $90 \mathrm{~mm}$ 인 중공축의 해석결과, 축의 몸체 및 필렛 부의 최대 응력 $92.807 M p a$, 베어링 시트 부의 최대 응 력 $111.91 \mathrm{Mpa}$, 중량 $12.399 \mathrm{kN}$ 이 도출되었다.

중공축의 몸체 및 필렛 부에 작용하는 응력은 중실축 에 비해 약 $40.12 \%$ 가 증가하였으며, 베어링 시트 부에 작용하는 응력은 약 $27.03 \%$ 가 증가하였다. 또한, 중량은 약 $8.19 \%$ 가 감소하였다.

베어링 시트 부를 제외한 나머지 부분은 EN13103에 서 규정하는 허용응력의 최대치( $55.91 \%)$ 를 만족하므로 본 설계에서 제외하였다.

중공축의 베어링 시트 부에 작용하는 응력은 EN13103 에서 규정한 허용응력 $92 \mathrm{Mpa}$ 을 초과한다. 따라서 베어 링 시트 부에 작용하는 응력을 줄이기 위해 Fig. 9와 같 은 캡을 축 내부에 삽입하였다.

\subsection{3 캡에 대한 해석조건 및 결과}

캡의 해석에 사용된 재질은 $\mathrm{SM} 45 \mathrm{C}$ 이며 탄성계수는 $205 G p a$, 푸아송 비 0.29의 물성치가 사용되었다.

차축과 캡의 접합은 마찰을 무시한 Bonded를 사용하 였으며 매쉬의 크기는 $5 \mathrm{~mm}$ 로 하여 해석하였다.

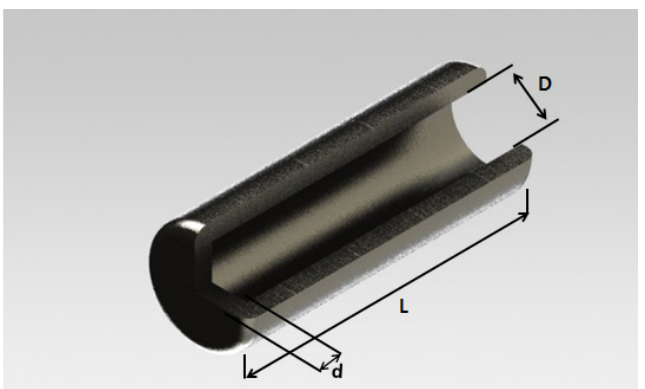

[Fig. 9] Design factors of the cap for wheel and axle 


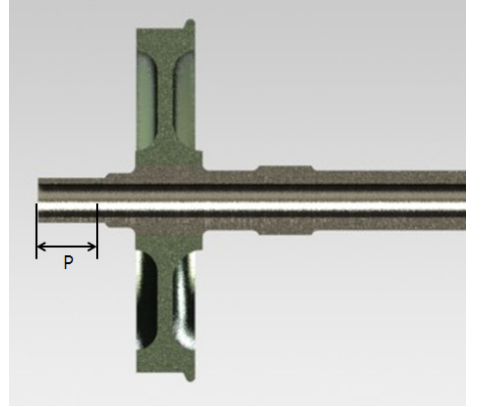

[Fig. 10] Position of the cap for wheel and axle

캡의 설계요소들은 Fig. 9, Fig. 10과 같이 캡의 길이 (L), 캡의 내경(D), 캡의 재료(M), 양 끝단을 기준으로 캡 이 떨어진 거리(P), 캡의 필렛(R), 캡의 응력을 감소시킬 목적으로 설치한 측벽의 개수 $(\mathrm{W})$, 측벽의 두께(d)로 나타 낼 수 있다.

설계요소의 조건 및 해석결과는 [Table 3]과 같다.

[Table 3] Factor conditions and analysis results

\begin{tabular}{|c|c|c|c|}
\hline \multirow[b]{2}{*}{ Factor } & \multirow[b]{2}{*}{ Condition } & \multicolumn{2}{|l|}{ Result } \\
\hline & & $\begin{array}{l}\text { seats except axle } \\
\text { bearing stress }\end{array}$ & weight \\
\hline $\mathrm{L}$ & $200 \mathrm{~mm}$ & \multirow{7}{*}{ 76.356Mpa } & \multirow{7}{*}{$12.593 k N$} \\
\hline $\mathrm{D}$ & $30 \mathrm{~mm}$ & & \\
\hline$M$ & SM45C & & \\
\hline $\mathrm{P}$ & $120 \mathrm{~mm}$ & & \\
\hline $\mathrm{R}$ & $5 \mathrm{~mm}$ & & \\
\hline $\mathrm{W}$ & 2 개 & & \\
\hline $\mathrm{d}$ & $5 \mathrm{~mm}$ & & \\
\hline
\end{tabular}

캡을 삽입한 윤축의 베어링 시트 부가 갖는 응력분포 에 대한 해석은 Fig. 11과 같다.

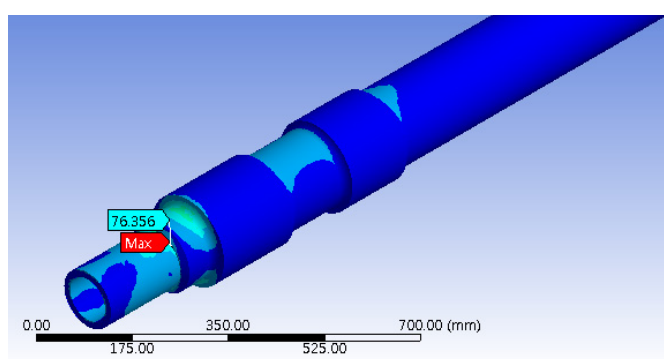

[Fig. 11] Analysis results for stress of bearing seat

[Fig. 11]은 베어링 시트부에 최대응력이 작용하는 부 위를 나타낸다.

축의 응력을 줄이기 위해 삽입한 캡의 응력분포는 [Fig. 11]과 같다.

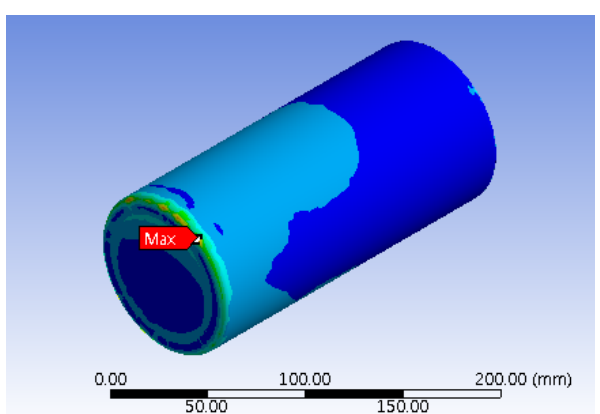

[Fig. 12] Analysis results for stress of cap

[Fig. 12]는 응력이 캡의 필렛에서 응력이 집중 됨을 나타낸 것이다. 상기 최대응력은 $174.56 M p a$ 으로 도출 되었다. 이는 $\mathrm{SM} 45 \mathrm{C}$ (normalizing)의 강도 $569 \mathrm{Mpa}$ $(30.68 \%)$ 을 만족하였다.

또한 $\mathrm{SM} 45 \mathrm{C}$ 의 회전굽힘시험에서 평활재료 시험편은 S-N선도( $10^{6}$ 사이클)에서 약 $320 \mathrm{Mpa}$ 의 강도를 갖는다. 이를 근거로 캡은 피로와 강도에 대하여 안정성을 만족 한다고 볼 수 있다[9].

캡을 삽입한 축은 중공축에 비해, 베어링 시트 부에 작 용하는 응력이 $32 \%$ 감소되었지만, 중량은 $1.5 \%$ 증가하 였다.

또한 중실축에 비해, 베어링 시트 부 응력은 $11.30 \%$ 감소하였고, 중량은 $6.75 \%$ 감소하였다.

결론적으로 캡을 삽입한 축은 중실축에 비해 중량을 감소시켰고, 중공축에 비해 중량증가 대비 강도증가량이 높아 효율적인 윤축 구조임을 알 수 있다.

\section{4. 결론}

본 연구는 철도차량에서 쓰이는 윤축의 경량화에 대한 연구로서 창의적 문제 해결 이론인 TRIZ를 활용하여 윤 축에 삽입 가능한 캡을 설계하였다. 또한, 설계된 캡의 성 능 검증을 위해 $\mathrm{ANSYS}$ 를 활용하여 기존의 축과 비교 해 석하였다.

1) 캡을 삽입한 축은 중실축에 비해 작용하는 응력을 $11.3 \%$, 중량은 $6.75 \%$ 를 감소시켰다.

2) 캡을 삽입한 축은 중공축에 비해 중량은 $1.5 \%$ 증 가시켰지만, 작용하는 응력은 $32 \%$ 를 감소시켰다.

3) 캡의 필렛에 작용하는 최대응력은 SM45C 항복응 력의 $55.91 \%$ 로서 강도에 대한 안전성을 만족한다. 


\section{References}

[1] D. W. Lee, J. N. Kim, S. S. Cho, "A Study on Safety Estimation of Railroad Wheel", Journal of the Korea Academia-Industrial cooperation Society, Vol. 11, No. 4, pp.1178-1185, 2010.

[2] S. W. Han, S. W. Son, H. S. Jung, "Weight Reduction of an Urban Railway Axle Based on EN Standard", Transactions of KSME A, Vol. 36, No.5, pp.579-590, 2012.

[3] S. W. Son, H. S. Jung, S. W. Han, J. S. Kim, T. S. Kwon, "Structural Analysis of Hollow Railway Axle Design", KSAE 2012 Annual Conference, pp.1764-1768, 2012.

[4] J. C. Lee, Y. J. Huh, "A Study on Supplementary Features of Injection-Molded Parts Using TRIZ and Axiomatic Design", The Korea Academia-Industrial cooperation Society 2010 Semiannual, pp.1145-1148, 2010

[5] O. W. Jeon, I. K. Jang, H. J. Kim, S. H. Ji, "Developing DoorTrim Design for Crash Absorption Using The TRIZ method", KSAE 2007 Annual Fall Conference, pp.54-60, 2007.

[6] H. G. Kim, "The basic theory and application of the finite element method", Transaction of the KSAE, Vol.16, No.4, pp.339-344, 1976.

[7] Y. J. Huh, S. D. Hong, "A Study on TRIZ Applied Design for Photovoltaic System with Reversal Tracking Reflecto", Journal of the Semiconductor \& Display Technology, Vol.11, No.3, pp.27-31, 2012.

[8] E. S. Jeon, Y. S. Haam, H. M. Hur, B. B. Kang, "Structural Strength Analysis and Static Load Test of a Wheelset of Korean High Speed Rail for Measuring Wheel/Rail Force", Transactions of Spring Conference of Korean Society for Railway(2), pp.898-903, 2002.

[9] Y. B. Lee, "Characteristics of Fatigue Behavior and Fracture Surfaces by Rotary Bending Test in SM45C Welding Zone", Journal of the Korean Society of Machine Tool Engineers, pp.26-32, 2010.

\section{허 용 정(Yong-Jeong Huh)}

[종신회원]

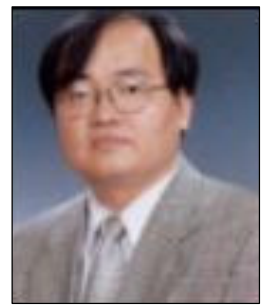

- 1980년 2월 : 부산대학교 기계설 계학과 (공학사)

- 1982년 2월 : 서울대학교 대학원 기계설계학과 (공학석사)

- 1991년 2월 : 한국과학기술원 기 계공학과 (공학박사)

- 1993년 1월 현재 : 한국기술교육 대학교 메카트로닉스공학부 교수

<관심분야>

지능형 설계, 사출성형의 $\mathrm{CAD} / \mathrm{CAE}$, 기계설계, 반도체 패키징

\section{김 재 민(Jae-Min $\mathrm{Kim})$}

[준회원]

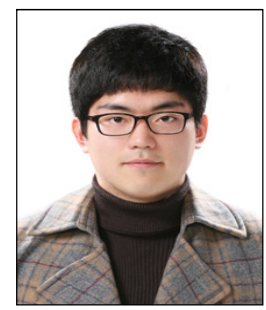

- 2008년 2월 현재 : 한국기술 교육대학교 메카트로닉스 공학 부 재학

<관심분야>

환경공학, 기계재료학, 기계설계

홍 성 도(Sung-Do Hong)

[준회원]

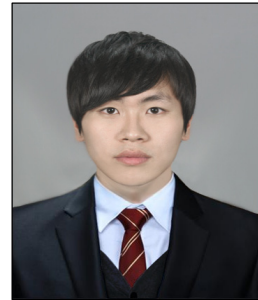

2004년 2월 현재 : 한국기술 교육대학교 대학원 메카트로닉 스 공학부 재학

<관심분야>

TRIZ, 창의적 설계, OLED 